\title{
COMPARATIVE ASSESSMENT OF DIFFERENT DEGREE OF RETENTION OF ERA ATTACHMENT ON THE SUPPORTING STRUCTURES OF IMPLANT SUPPORTED MANDIBULAR OVERDENTURE
}

\author{
Mona Mohamed Aboelnagga* and Mahmoud El Moutassim Bellah El Homossany**
}

\begin{abstract}
Objectives: This research was carried out to evaluate the effect of different degree of resiliency of ERA attachment; white and grey nylon male components in mini-implant retained mandibular overdenture on the peri-implant crestal bone level.
\end{abstract}

Materials and Methods: Twenty completely edentulous patients with maladaptive experience of wearing mandibular dentures were selected to participate in this study. Patients participating in this study were rehabilitated by maxillary complete denture and implant retained mandibular overdenture by four mini-implants with ERA head abutments. For all selected patients four mini implants $2.2 \mathrm{~mm}$ in diameter and $14 \mathrm{~mm}$ in length (ZIMMER ERA) were inserted in the interforaminal area following the non-submerged flapless surgical approach with the help of a modified transparent acrylic template. Standard clinical and laboratory techniques were followed for denture construction for all patients. Patients were randomly divided into two equal groups according to the resiliency of the male nylon insert. A white replacement insert was seated into the metal housing for group I, while a grey replacement insert was used for group II. Mesial, distal, buccal and lingual marginal bone height around the mini implants were evaluated, using the linear measurement system of the software (Ondemand 3D) with flat panel detector supplied by the cone beam CT. The measurements were carried out at the end of each follow-up appointment (at overdenture insertion, 6, 12 and 18 months post insertion). The marginal bone loss at different intervals was obtained by calculating the difference in bone height at that interval from the base line measurement and statistically analyzed.

Results: The results of this study showed that there was statistically significant increase in the marginal bone height loss around the mini implants in both groups at the end of 18 months follow up. Comparing the two studied retentive elements of ERA attachment; statistically significant difference between the two groups was found at the end of 18 months follow up period, where group I showed less bone resorption in comparison to group II. There was also significant difference between both groups concerning the distal and the labial surfaces after 18 months.

* Assistant Professor of Prosthodontics, Faculty of Dentistry, Ain Shams University

** Lecturer of Prosthodontics, Faculty of Dentistry, Ain Shams University 
Conclusion: ERA attachments in mini-implant retained mandibular overdenture fulfil the criteria of implant success as indicated by the measured amount of marginal bone loss. ERA attachments provide adequate retention and have the ability to control the amount of bone loss by changing the retentive elements. The lesser the retention the less significant bone loss around the implants

KEY WORDS: Mini-implants, overdenture, ERA attachment, Marginal bone level

\section{INTRODUCTION}

An implant-retained overdenture constitutes a good management choice when edentulous patients are unsatisfied with their conventional complete dentures. Many authors have investigated the impact of implant-supported dentures compared to conventional dentures. Implant-supported dentures including either complete overdentures or a hybrid prosthesis significantly improve the quality of life for edentulous patients compared with conventional complete dentures. ${ }^{(1,2)}$ Preservation of the residual ridges, tactile discrimination, improvement of the masticatory performance, increased retention and stability, maintaining occlusion and vertical dimension have been reported in the literature as their advantages. ${ }^{(3-4)}$

The standard root form implant, $3.75 \mathrm{~mm}$ in width, has significant functional limitation in patients with knife-edge ridge for successful placement without the need for additional bone grafting. From a biomechanical point of view, a residual plate that is less than $2 \mathrm{~mm}$ in thickness could have an adverse effect on bone stress levels and crestal bone maintenance. ${ }^{(5)}$

Recently mini-implants ranging in diameter from $1.8 \mathrm{~mm}$ or slightly more than $2 \mathrm{~mm}$ have been used to support conventional denture with atrophied mandible without bone grafting. (6) These miniimplants were formerly introduced to support fixed provisional restorations. Recently successful oral rehabilitation with mini-implants in more definitive treatments has been reported for partially and completely edentulous patients. ${ }^{(7,8)}$
The advantages of using mini-implants include simplicity of placement, minimally invasive surgery and significantly shorter healing periods than those for conventional implants. ${ }^{9}$ However, miniimplants have a reduced diameter and surface area; therefore, they are subjected to greater occlusal loading, which may lead to mechanical failure, such as deformation and fracture. Nevertheless, when four mini-implants were used to support and retain complete overdenture for three years, high survival rates were reported irrespective of whether miniimplants were immediately or early loaded $(91.7 \%$ and $96.7 \%$, respectively). ${ }^{(10)}$

Attachments used in conjunction with implants were found to enhance the retention, the stability and support of overdentures together with the implants, thus extending their longevity. ${ }^{(11)}$

A wide variety of commercially available attachment systems is used to connect implants to overdentures. Most commonly used attachments include stud, bar, magmatic, and telescopic attachments. Each of these types has owned its advantages, disadvantages, and special requirements efficiently to be used. The selection of attachment system depends on the amount of retention needed, available inter arch space, manual dexterities of the patient, skills of the dentist and finally the cost. ${ }^{(12)}$

Selection of an attachment system that is suitable for a specific clinical situation is sometimes difficult. A good knowledge of the different systems and their mechanical properties, and the way in which they distribute load, is important. ${ }^{(13)}$

Small diameter implants are available as onepiece implant with rubber O-ring attachment 
housed in the fitting surface of the denture that is made of high elastic polymers and are used as retention components. The advantages of this type of attachment are the ease in changing the O-rings, the wide range of movement, low cost and different degree of retention for the prosthesis. ${ }^{(14,15)}$

The extra-coronal resilient attachment system (ERA) has been introduced with varying degrees of resiliency. It offers vertical resiliency and universal stress relief for use where a resilient prosthesis is indicated. (16) ERA implant abutment system is composed of two basic elements: a titanium female and a nylon male. Lateral forces are not entirely transmitted to the abutment because the male part can bend during slight movement of the denture. This attachment overcomes the space problem because all its bulk is housed within the root portion of the abutment. Low-profile implant ERA overdenture attachment was used to reduce the abutment restoration height on implants. ${ }^{(17)}$

ERA male part is made of nylon that is colour coded by the manufacturer according to the amount of retention (white, orange, blue and grey); recently two more retentive elements have been added: yellow and red (hierarchy of retention from light to heavy). This feature allows the clinician to vary the retention if necessary. The mechanism for varying the amount of retention between the colours is that the nylon male components become increasingly oversized in comparison to the stainless steel with titanium nitride coating female components. This creates more surface area, a tighter fit, and more retention. ${ }^{(18)}$ In addition the black male can be used for processing in the overdenture. It creates an undercut male-retention socket in the denture acrylic resin and allows for the creation of $0.4 \mathrm{~mm}$ of resiliency in the final restoration. ${ }^{(19)}$

The primary retention of ERA comes from the friction between the metal female and nylon male on the inner side of the ring; however, the wall outside the ring may play a role in the retention as well. ERA males act as a hybrid ball and socket attachment, allowing vertical resiliency and universal stress relief for use when a resilient prosthesis is indicated. ${ }^{(19)}$

Incorporating ERA attachment as a retentive component provides positive, stable retention and support for the denture and offers several levels of retention according to the patient's needs and the level of retentiveness of the ERA attachment placed into the denture. ${ }^{(14)}$ The replaceable nylon matrix having various elasticity, makes it possible to adjust the retention force depending on the actual need. ERA attachments are presented as especially advanced, as far as adaptation to resiliency of denture foundation, since the denture has the possibility to prosthesis settling in the direction of implant axis. ${ }^{(20)}$

A study examined overdentures retained by bar/clip attachments, ERA attachments and a combination of a bar/clip with distal ERA attachments in photoelastic model. It was concluded that ERA attachments alone tended to provide the most equitable transfer of load to the bone surrounding the implants. ${ }^{(21)}$ Another study revealed that ERA white attachment transmits less strain to the peri-implant bone than ball attachment, on both vertical and oblique loading. ${ }^{(22)}$ A study comparing the retentive force of both ERA grey attachment system and ball attachment system, found that the ERA grey was more retentive in both axial and oblique directions. ${ }^{(23)}$

The ultimate choice of attachment type should be based on clinical performance of the attachments regarding the functional loads onto the implants and surrounding tissues; patients' satisfaction with treatment, the technical problems, and maintenance service as well as attachment costs. Although in-vitro studies have been published comparing retention and load transfer of ERA attachment and other attachments, studies on the effect of ERA attachment resiliency in mini-implant retained 
mandibular overdenture on peri-implant bone loss is absent from the literature. Accordingly, the aim of this study was to evaluate the effect of two different degree of resiliency of ERA attachment in mini-implant retained mandibular overdenture on the peri-implant marginal bone height using Conebeam computed tomography.

\section{MATERIALS AND METHODS}

Twenty male patients having problems adapting to theirconventional complete dentures were selected to participate in this study. Age of the selected patients ranged between 50-65 years, they exhibited Angle class I ridge relationship, patients had either rounded or U-shaped alveolar arches, adequate inter arch space, no history of para-functional habits, and they also had no temporomandibular joint disorders. On clinical examination, the residual alveolar ridge exhibited adequate height and width and was covered with firm fibrous mucoperiosteum. All patients were in a good, acceptable general health, with no psychological disorders or neuromuscular incoordination.

All patients participating in this study were rehabilitated by mucosa supported maxillary complete denture and implant retained mandibular overdentures where four mini-implants* retained by ERA attachment were inserted in the inter-foraminal region.

Detailed information about the treatment was given to all patients; the surgical and prosthetic steps, the risks and benefits were explained. All patients were motivated to the treatment and were informed that they would be a part of a study that needs their best co-operation. All patients agreed to share and follow the instructions given to them in the form of signed consent.

Upper and lower primary impressions were made using Alginate** in properly selected and modified stock tray. Provisional jaw relation record was made at the predetermined occlusal vertical dimension. The maxillary and mandibular casts were mounted on a mean value articulator to ensure parallelism between the upper and lower ridges, Angle's class I skeletal maxilla-mandibular relationship and the presence of at least $15 \mathrm{~mm}$ inter-arch space in the anterior region.

Pre-operative cone beam computed tomography ${ }^{* * *}$ was carried out for all patients to evaluate the bone quality (classes 1-2 were selected according to Lekholm and Zarb) ${ }^{(30)}$ Evaluation of the available bone height and width in the area between the mental foramina was done to reveal at least about $4 \mathrm{~mm}$ width and $16 \mathrm{~mm}$ height and to locate the position of mental foramina.

Upper and lower conventional complete dentures were constructed to all patients following the same basic principles. Modified cusped cross-linked acrylic teeth $^{* * * *}$ were used and balanced on semiadjustable articulator ${ }^{* * * * *}$ for centric and eccentric positions following the lingualized concept of occlusion. Dentures were clinically remounted to refine the occlusion, ensure free non-interfering contact in centric relation and during all excursive mandibular movements.

Radiographic stent was fabricated by duplication of the patient's lower denture into clear acrylic resin ${ }^{* * * * * *}$. Then the proposed implant sites of the four mini-implants were marked on the surgical

\footnotetext{
* ZIMMER ERA MDI,USA.

** Alginate, Cavex Holland BV.

*** I-CAT FLX cone beam 3D dental imaging

**** Vita-pan acrylic teeth, Vita Bad Sackingen- Germany.

***** Denatus articulator Type ARH Jakobsal. Svagen 14-16. S12653, Hagersten. Sweden.

****** QC 20. DentSply Ind.Com. Ltda. Petropolis, RJ, Brazil
} 


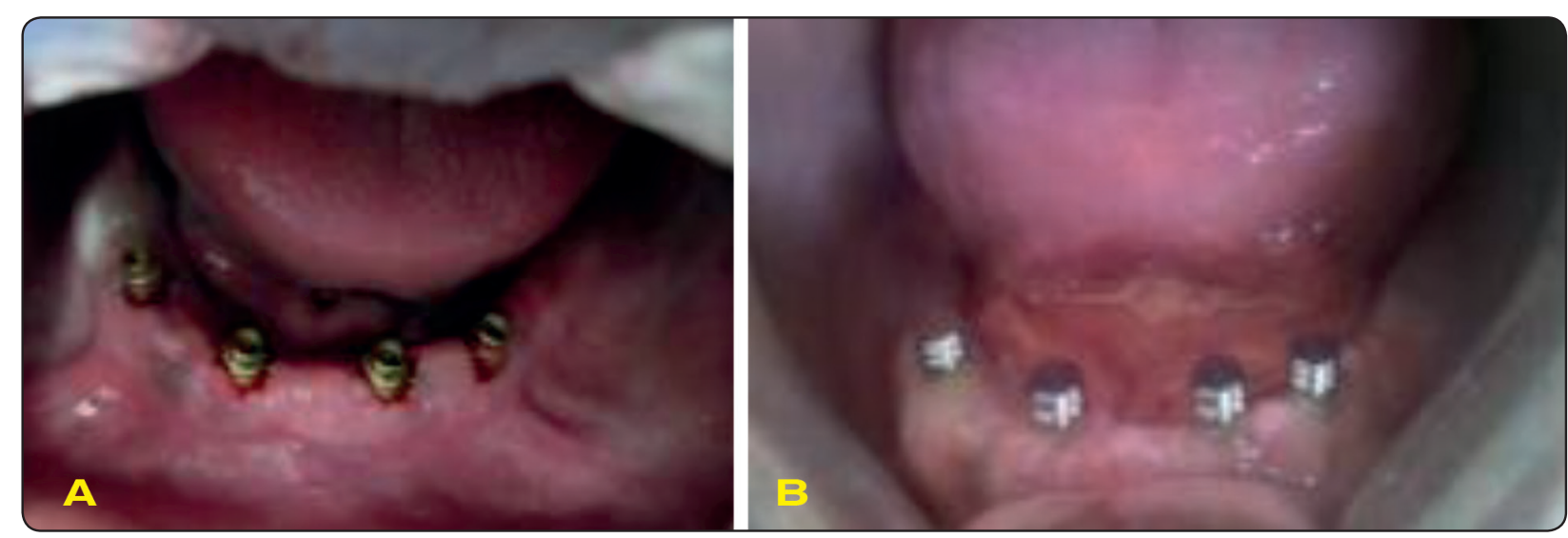

Fig (1): A) Four mini-implants with ERA attachment were inserted. B) The metal housings were seated on the ERA attachment heads.

stent to be equidistant from each other at the canines and first premolars region and holes were made to provide access during surgical drilling.

For all selected patients four mini-implants 2.2 $\mathrm{mm}$ in diameter and $14 \mathrm{~mm}$ in length (ZIMMER ERA MDI, USA.) were inserted following non-submerged flapless surgical approach with the help of the modified transparent acrylic template. Fig (1-A)

Next day to the surgery, the metal housings were seated on the ERA attachment heads. Fig (1-B) The fitting surface of the mandibular denture was relieved opposite to the mini-implants' sites guided by the marks transferred by the pressure indicating paste brushed on the metal housings placed on the mini-implants, the denture was tried in the patient's mouth until the denture was completely seated.

Small sterile rubber dam pieces were punched out and placed through the ERA attachment heads. The housings were then picked up to the fitting surface of the mandibular denture using self-cure acrylic resin* while the patient was holding the dentures in centric occluding relation. The excess acrylic resin was trimmed; the occlusion was refined.

The black processing male was removed from the metal housing and replaced by the nylon

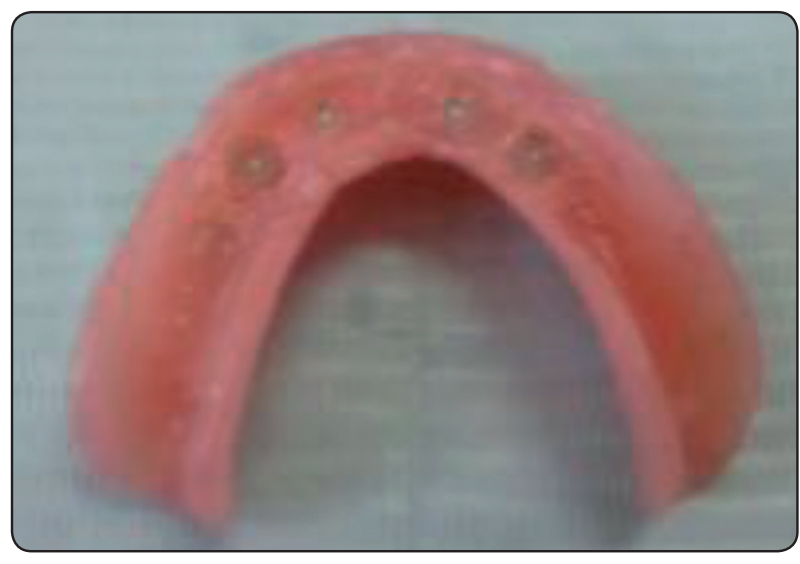

Fig (2): The pick-up of the housing to the fitting surface of the mandibular denture

replacement insert. Patients participating in this study were randomly divided into two equal groups, ten in each, according to the resiliency of the male nylon insert used.

A white replacement insert was seated into the metal housing for group I patient's fig (2), while a grey replacement insert was seated into the metal housing for group II patients.

Emphasis on oral hygiene instructions was given to all patients and they were frequently recalled for inspection and post insertion adjustments if needed. 
Follow up visits were scheduled 6, 12 and 18 months after overdenture insertion for making the radiographic records.

\section{Radiographic evaluation:}

The mesial, distal, buccal and lingual marginal bone height loss around the four mini-implants were measured using cone beam computed tomography at the time of overdenture insertion, 6, 12 and 18 months after overdenture insertion, to calculate the marginal bone height changes during the follow-up period.

In the cone beam's sagittal plane, the distal and mesial marginal bone height around the miniimplants were evaluated while the buccal and lingual marginal bone height were evaluated in the frontal plane. First, a line was drawn horizontally tangential to the apex of the mini-implant and perpendicular to its long axis. A line was then drawn tangential to the distal surface of the mini implant, parallel to the long axis and extended from the highest level of the alveolar crest to the horizontal line. The same

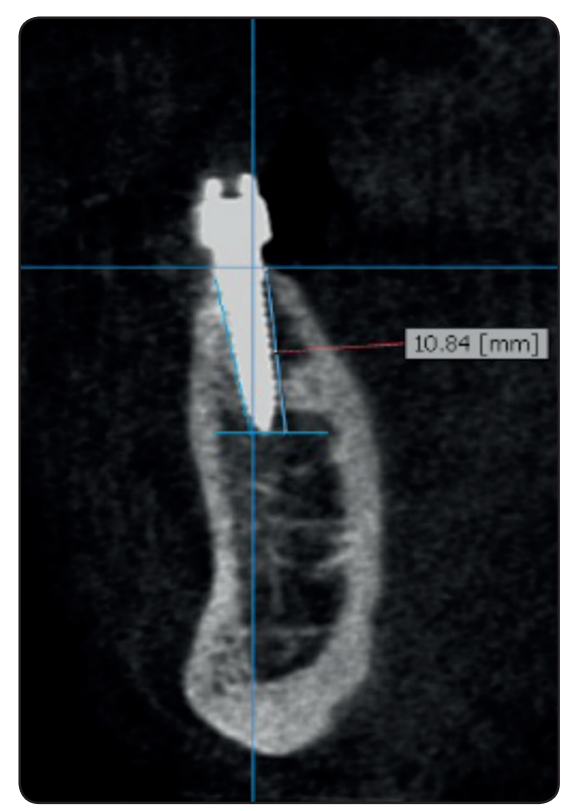

Fig (3): The marginal bone height around the mini implants were measured.

(B) IBM Corporation, NY, USA.

®SPSS, Inc., an IBM Company. procedure was repeated for the mesial, buccal, and lingual aspects of the four mini-implants. Fig (3) The measures of these lines were collected, compared, tabulated and statistically analysed.

\section{RESULTS}

Numerical data were explored for normality by checking the data distribution, calculating the mean and median values, evaluating histograms and normality curves and using Kolmogorov-Smirnov and Shapiro-Wilk tests.

Data were presented by mean and standard deviation. Independent t test was used for comparison between groups and unpaired t test was used for comparison within the same group. The significance level was set at $\mathrm{P} \leq 0.05$. Statistical analysis was performed with IBM ${ }^{\circledR}$ SPSS ${ }^{\circledR}$ Statistics Version 20 for Windows.

The results showed that in the first six months, the mean bone loss showed the same values $0.41 \mathrm{~mm}$ for both groups. The period from 6-12 and 12-18 months, showed no statistically significant difference between the two groups where $\mathrm{P}$ value was more than 0.05. As shown in table (1)

The results of this study also showed that there was statistically significant increase in the marginal bone height loss around the mini implants in both groups at the end of 18 months follow up. In group I total bone loss was $0.6 \mathrm{~mm}$ while in group II was $0.67 \mathrm{~mm}$ and the $\mathrm{P}$ value was 0.039 . There was also significant difference between both groups concerning the distal and the labial surfaces after 18 months, where $\mathrm{P}$ value was 0.39 . As shown in table (1)

Comparing within the same group using unpaired t test showed that the total bone loss in the first 6 months compared to the total bone loss in the interval from 6-12 is statistically significant in both group I and II. While the total bone loss from 
the interval 6-12 compared to $12-18$ months is not statistically significant in both groups concerning the mesial, distal, labial and lingual aspects of the implants and the $\mathrm{P}$ value was less than 0.005 . As shown in table (2)
Comparing the total bone loss from the beginning of the treatment till the end of the follow up inside each group showed a clinical significance. As shown in table (1)

TABLE (1) Mean differences and standard deviation values of marginal bone height changes for group I and group II among the follow up period.

\begin{tabular}{|c|c|c|c|c|c|c|}
\hline \multirow{2}{*}{ Interval } & \multirow{2}{*}{ Aspect } & \multicolumn{2}{|c|}{ Group I } & \multicolumn{2}{|c|}{ Group II } & \multirow[t]{2}{*}{ P value } \\
\hline & & Mean & S.D & Mean & S.D & \\
\hline \multirow{5}{*}{ 0-6 months } & Labial & 0.35 & 0.10 & 0.40 & 0.12 & 0.325 \\
\hline & Lingual & 0.42 & 0.11 & 0.45 & 0.11 & 00549 \\
\hline & Mesial & 0.41 & 0.15 & 0.44 & 0.13 & 0.638 \\
\hline & Distal & 0.45 & 0.12 & 0.38 & 0.10 & 0.174 \\
\hline & Total & 0.41 & 0.12 & 0.41 & 0.09 & 1 \\
\hline \multirow{5}{*}{ 6-12 months } & Labial & 0.45 & 0.12 & 0.38 & 0.10 & 0.157 \\
\hline & Lingual & 0.41 & 0.12 & 0.43 & 0.09 & 0.678 \\
\hline & Mesial & 0.12 & 0.10 & 0.15 & 0.09 & 0.489 \\
\hline & Distal & 0.11 & 0.09 & 0.13 & 0.12 & 0.694 \\
\hline & Total & 0.15 & 0.12 & 0.14 & 0.13 & 0.86 \\
\hline \multirow{5}{*}{$\begin{array}{c}\text { 12-18 } \\
\text { months }\end{array}$} & Labial & 0.14 & 0.11 & 0.12 & 0.15 & 0.738 \\
\hline & Lingual & 0.13 & 0.11 & 0.14 & 0.12 & 0.848 \\
\hline & Mesial & 0.11 & 0.09 & 0.13 & 0.07 & 0.589 \\
\hline & Distal & 0.10 & 0.08 & 0.12 & 0.08 & 0.578 \\
\hline & Total & 0.12 & 0.10 & 0.11 & 0.10 & 0.826 \\
\hline \multirow{5}{*}{ 0-18 months } & Labial & 0.58 & 0.10 & 0.68 & 0.11 & $0.039 *$ \\
\hline & \begin{tabular}{|l} 
Lingual \\
\end{tabular} & 0.59 & 0.07 & 0.70 & 0.07 & 0.1825 \\
\hline & Mesial & 0.63 & 0.08 & 0.66 & 0.12 & 0.27 \\
\hline & Distal & 0.6 & 0.10 & 0.62 & 0.08 & $0.039 *$ \\
\hline & Total & 0.6 & 0.09 & 0.67 & 0.10 & $0.039 *$ \\
\hline
\end{tabular}

TABLE (2) Comparing the total bone loss in the first and second group between different time intervals

\begin{tabular}{|c|c|c|}
\hline Interval Group I & Interval Group I & P value \\
\hline $0-6$ months & 6-12 months & 0.0115 \\
\hline 6-12 months & $12-18$ months & 0.25 \\
\hline $0-6$ months & $12-18$ months & P value \\
\hline Interval Group II & Interval Group II & 0.0020 \\
\hline $0-6$ months & 6-12 months & 0.31 \\
\hline 6-12 months & $12-18$ months & 0.0001 \\
\hline $0-6$ months & $12-18$ months & \\
\hline
\end{tabular}




\section{DISCUSSION}

The traditional clinical approach to patients who cannot wear complete dentures has been either to modify the denture construction technique or, when the problems are of a technical or morphological nature, to prescribe preprosthetic surgery. This surgery is undertaken to enlarge the available denturebearing area. It usually involves vestibuloplasty, or ridge augmentations. ${ }^{(24)}$

The use of implant retained mandibular overdenture results in a significant improvement of the masticatory performance by $20 \%$. Less complains and higher overall satisfaction was reported when compared with conventional complete denture. ${ }^{(25)}$

Standard clinical and laboratory techniques were followed for the construction of the dentures for all patients. Also, the same materials were used as feasible as an attempt to eliminate any factor that might affect the results of this study.

Pre-operative cone beam computed tomography was used to determine the position and the desired angulations of the mini-implants, as anatomy and bone quality affect the outcome and ease of surgical placement of mini implants. Adequate bone height and width are needed for mini-implant placement. ${ }^{(26)}$

Implant success is highly reliant on the volume and quality of the peri-implant bone. Bone quality in the anterior area of the mandible is much better than that in the posterior region. ${ }^{(5)}$ Implant placement in the inter-foraminal area is less critical than in other areas of the mandible, and a success rate of $\geq 95 \%$ was reported for implants placed in this region. ${ }^{(27)}$

Mini-implant reduces bleeding, decreases post-operative discomfort, shortens healing time and provides immediate loading. ${ }^{(28)}$ Despite the advantages provided by mini-implant, decreasing the diameter increases the risk for implant fracture because of reduced mechanical stability and the risk of over loading. ${ }^{(29,30)}$ Thus, it is recommended to increase the number of implants with maximum length to improve the initial stability. ${ }^{(31)}$

Sufficient number of mini-implants must be placed to adequately distribute loads generated during mastication. Using multiple mini-implants to retain removable prostheses reduces the forces experienced by individual mini-implants. If too few mini-implants are used, cyclic occlusal loading may fatigue the small-diameter implant neck to the point of fracture. ${ }^{(32)}$ Thus to compensate for reduced mini-implants diameter and surface area, four miniimplants with maximum length (according to the available ridge height) were inserted instead of the conventionally used two implants to support mandibular overdentures. ${ }^{(32)}$

The positioning of mini-implants in the canine and $1^{\text {st }}$ premolar area enhances free overdenture rotation during posterior loading, with twist-free load transmission to the implants. In contrast, equal distribution of mini-implants in the inter-foraminal area increases the chance of mini-implants overloading by rotation of the distal cantilevered portions of mandibular overdenture due to mucosal resiliency. ${ }^{(33)}$

Retention should not be the only factor to consider when designing an implant-retained overdenture. As the patient functions with an implant-retained overdenture, loads are transmitted to the alveolar bone surrounding the implants, as well as to the abutments and residual ridges. It is important not to cause unfavorable loads on the implant abutments that house the attachments, as these loads can be detrimental to the osseointegrated implants. ${ }^{(34)}$

ERA System for implant-supported overdentures is a unique and easy system to use. It incorporates the concepts of tissue resiliency, adjustable retention, and stability for constructing an implant supported prosthesis with high patient acceptance. It has the advantage of minimal repairs and adjustments by virtue of the replacement technique for the nylon males. ${ }^{(35)}$ 
The direct pickup technique was preferred over the indirect technique in incorporating the metal housings to avoid the possible discrepancies that may occur if indirect technique was used. Small sterile rubber dam pieces were punched out and placed through the ERA attachment heads for blocking out any undercuts that acrlic may flow into and prevent removal of the denture thus ensuring that the prosthesis can be fully seated on the tissues without being held up by interference with the attachment.

The fitting surface of the lower denture was drilled by large round bur opposite to the miniimplants positions and tried in the patient's mouth until the denture was seated passively. Self-cure acrylic resin was then mixed and applied to the relieved areas over the mini implants in the dough stage. The denture was seated in the patient's mouth; patients were instructed to close in centric occluding relation until complete polymerization took place to preserve correct centric relation and vertical dimension established.

The black processing male nylon cap of the ERA metal housing was replaced with the white one after the pickup procedure in group I patients; this activates the $0.4 \mathrm{~mm}$ vertical resiliency feature of the ERA attachment while in group II was replaced with grey one.

With few clinical results available on the radiographic evaluation on the implants retaining ERA overdenture attachments, the goal of this study was to compare the marginal bone height around two different ERA attachments white and grey to find which one is more favorable to use.

Optimum health is defined as the absence of pain or tenderness on function, zero mobility, less than $2 \mathrm{~mm}$ of radiographic bone loss from time of placement, and no history of exudate. The results of this current study revealed that the use ERA attachment fulfils the criteria of implant success as indicated by the measured amount of bone loss in both groups. The significant amount of bone loss fully comply with success criteria mentioned by Cox and Zarb ${ }^{(36)}$, Albrektsson ${ }^{(37)}$ et al. and VonWowern and Gtfredsen ${ }^{(38)}$, and were within the permissible range previously reported to occur within the first year of implant placement.

The acceptable range of crestal bone height loss in mini-implants retained mandibular overdenture could be attributed to several factors. The flapless placement technique of mini-implants causes minimal disruption to the periosteum, preserves peri- and endosteal blood supply, and preserves the bone height around the implants after surgery. ${ }^{(39)}$ Moreover, the low-profile design of ERA and the resilient connection which provides a space of 0.2 $\mathrm{mm}$ that allows hinge movement in any direction that may explain this finding ${ }^{(17,20)}$

Although the results of this study showed significant peri-implant bone loss in the first year after loading and the results of this study revealed insignificant bone loss in subsequent six months for the studied patients.

The statistically significant decrease in periimplant bone height change for the two studied groups might be due to surgical trauma, bone osteotomy, and healing process. Also, it might be considered an immediate bone reaction after insertion of the prosthesis that attributed to the healing and reorganization following trauma to the bone and periosteum combined with remodelling due to implant loading. ${ }^{(39,40)}$

In a study accessing the influence of attachment wear on retention of mandibular overdenture, the ERA white, and ERA orange was tested. It was found that because of fatigue, after 2000 insertion and removal cycles, sudden decrease of retentive force was noticed for both the ERA white and ERA orange groups (46\% and $52 \%$ respectively). ${ }^{(41)}$

A study evaluated and compared the retentive capacity between two O-ring and O-SO system (Group I), and two ERA system types - white and grey retention caps - (Group II), it was concluded that all the attachment systems tested showed retention 
loss during the experiment; the ERA system showed, since the beginning, higher retention compared to the other systems and the grey colored attachment showed the best result in the end of the simulated use test. ${ }^{(42)}$

\section{CONCLUSION:}

From the results obtained in this research, it was concluded that ERA attachments can be used successfully in retaining and supporting mandibular complete denture. As retention was improved by using Grey code ERA attachment the changes in marginal bone height is increased than in White code; thus to improve retention it may affect the rate of bone resorption on long time of use, thus it is recommended to be used in certain indicated cases not routinely.

\section{REFERENCES}

1- Awad, MA., Lund, JP., Dufresne, E., Feine, JS. Comparing the efficacy of mandibular implant-retained overdentures and conventional dentures among middle-aged edentulous patients: satisfaction and functional assessment. Int $\mathrm{J}$ Prosthodont. 16, 117-122. 2003

2- Heydecke, G., Thomason, JM., Lund, JP. The impact of conventional and implant supported prostheses on social and sexual activities in edentulous adults: Results from a randomized trial 2 months after treatment. J Dent, 33 (8), 649-657,2005

3- Burns DR.: Mandibular Implant Overdenture Treatment: Consensus and Controversy. J Prosthodont. 9: 37-46, 2000.

4- Stellingsma K, Slagter AP, Stegenga B, Raghoebar GM\& Meijer HJ. Masticatory function in patients with an extremely resorbed mandible restored with mandibular implant-retained overdentures: comparison of three types of treatment protocols. J Oral Rehabil. 32: (6): 403-410 , 2005

5- Misch, C.E. Contemporary Implant Dentistry (3rd ed.). St Louis, Mo: CV Mosby; 2008: 293-313.

6- Minsk L. Interim implants for immediate loading of temporary restorations. Compend Contin Educ Dent.22: 186-194,2001.

7. Sendax VI. Mini-implants as adjuncts for transitional prostheses. Dent Implantol Update. 7:12-15,1996.
8- Dhaliwal JS., Albuquerque RF. Jr, Murshed M., Feine JS. Osseointegration of standard and mini dental implants: a histomorphometric comparison. Int J Implant Dent. Dec;3(1):15, 2017.

9- Steffen, R.P., White, V., Markowitz, N.R. The use of ball-clip attachments with an implant-supported primarysecondary bar overdenture. J Oral Implantol; 30: 234-239 , 2004.

10- Maryod, W.H., Ali, S.M., Shawky, A.F. Immediate versus early loading of minimplants supporting mandibular over dentures: A preliminary 3-year clinical outcome report. Int J Prosthodont; 27: 553-560, 2014

11- Steffen RP, White V, Markowitz NR. The use of ball clip attachments with an implant-supported primary-secondary bar overdenture. J Oral Implantol; 30: 234-239, 2004

12- Alqutaibi AY., Kaddah AF. Attachments used with implant supported overdenture International Dental \& Medical Journal of Advanced Research; 2, 1-5,2016

13- Warreth, A., Byrne, C., Alkadhimi, AF., Woods, E., Sultan, A. Mandibular implant-supported overdentures: attachment systems, and number and locations of implants - Part II Journal of the Irish Dental Association; 61 (3): 144-148, 2015

14- Kurtzman GM., Douglas D. Improving denture stabilization with the ERA Mini implant. Implant practice. 3 (6): 32-37, 2012.

15- Winkler S., Piermatti J., Rothman A., Siamos G. An overview of the $\mathrm{O}$ ring implant overdenture attachment. J Oral Implantol. 28 (2):82-86, 2002

16- Majer HJ. The Stern ERA attachment. Exacting retention made easy. J Can Dent Assoc; 58: 615, 1992

17 - Gamborena JI., Hazelton LR., NaBadalung D., Brudvik J. Retention of ERA direct overdenture attachments before and after fatigue loading. Int J Prosthodont.; 10(2):123130,1997

18- Chung KH., Chung CY., Cagna DR., Cronin RJ. Retention characteristics of attachment systems for implant overdentures. J Proshet Dent. 13(4):221-226, 2004

19- Hsu YT. Retention guide for resilient dental attachments. J Prosthet Dent. 92(1): 93-94, 2004

20. Żmudzki J. Can typical overdentures attachments prevent from bone overloading around mini-implants? Journal of evaluation of different attachment systems used. Achievements in Materials and Manufacturing Engineering, 43 (I2), December 2010 
21. Federick DR., Caputo AA. Effects of overdenture retention designs and implant orientation on load transfer characteristics. J Prosthet Dent. 76(6): 624-632, 1996

22- Ragab DA. Extracoronal Resilient Attachment versus Ball Attachment for Mini-Dental Implants Retained Mandibular Overdenture. M.Sc. Thesis. Ain Shams University. 2014.

23. KU YC., Shen YF., Chan CP. Extracoronal resilient attachments in distal extension removable partial dentures. Quintessence Int.; 31(5): 311-317, 2000

24- Froschl T., Kerscher A. The optimal vestibuloplasty in preprosthetics of the mandible. J Craniomaxillofac Surg. 25(2): 85-90, 1997

25- Stern MR. Forces on implant supporting overdentures: a preliminary study of morphologic and cephalometric considerations. Int J Oral Maxillofac Implants. 8(3): 254263,1993

26- Howerton WB., Mora MA. Advancements in Digital Imaging: what is new and on the horizon? J Am Dent Assoc. 139(1): 20-24, 2008

27- Chee, W., Jivrai, S. Treatment planning of the edentulous mandible. Br Dent J. 201: 337-347, 2006.

28- FKrennmair G, Weinlander M., Schmindinger S. Provisional implants for anchoring removable interim prostheses in edentulous jaws: a clinical study. Int J Oral Maxillofac Implants. 18: 582-588, 2003.

29- Dilek O. Required minimum primary stability and torque values for immediate loading of mini dental implants: an experimental study in nonviable bovine femoral bone. Oral Surg Oral Med Oral Pathol Oral Radiol Endod .105:2027,2008 .

30. Flanagan D., Ilies H., McCullough P., McQuoid S. Measurement of the fatigue life of mini dental implants: a pilot study. J Oral Implantol. 34:7-11, 2008.

31.Ahnn MR., An KM., Choi JH., Sohn DS. Immediate loading with mini dental implants in the fully edentulous mandible. Implant Dent.13:367-372,2004.
32- Flangan D. Implant Supported Fixed Prosthetic Treatment using very small diameter Implants. J Oral Implantol. 32(1): 34-37, 2006

33- ELsyad MA., Gebreel AA., Fouad MM., EL Shoukouki AH. The clinical and radiographic outcome of immediate loaded Mini-Implants supporting a mandibular overdenture. A 3year prospective study. J Oral Rehabil, 38: 827-834, 2011

34-Porter JA., Petropoulos VC., Brunski JB. Comparison of Load Distribution for Implant Overdenture Attachments. Int J Oral Maxillofac Implants. 17 :651-662, 2002

35- Kurtzman GM., Dompkowski D. Maximizing denture stability and retention. Dent Today. 28(7):92-96, 2009

36-Cox J., Zarb G. The longitudinal clinical efficiency of osseointegrated dental implants. A 3-yearreport. Int J Oral Maxillofac Implants. 2(2): 91-100, 1987.

37-Albrektsson T., Zarb G., Worthington P., Eriksson AR. The long-term efficacy of currently used dental implants: a review and proposed criteria of success. Int $\mathrm{J}$ Oral Maxillofac Implants. 1: 11-25, 1986

38- Von Wowern N., Gotfredsen K. Implant-supported overdentures, a prevention of bone loss in edentulous mandibles. A 5-year follow up study. Clin Oral Implants Res. 12(1): 19-25, 2001

39- Jeong SM., Choi BH., Li J., Kim HS., Ko CY., Jung JH., et al. Flapless implant surgery: an experimental study. Oral Surg Oral Med Oral Pathol Oral Radiol Endod. 104: 2428, 2007

40- Nishioka RS, Souza FA. Bone spreader technique: a preliminary 3-year study. J Oral Implantol. 35: 289-294, 2009

41- Rutkunas V., Mizutani H., Takahashi H. Influence of attachment wear on retention of mandibular overdenture. J oral Rehabil. 34(1):41-51, 2007

42- Bonachela WC., Pedreira AP., Marins L., Pereira T. Comparative evaluation of retention loss in four types of attachments used on overdentures in function of time of use. J Appl Oral Sci. Mar;11(1):49-54, 2003. 